\title{
Erratum to: Determination of glyphosate in groundwater samples using an ultrasensitive immunoassay and confirmation by on-line solid-phase extraction followed by liquid chromatography coupled to tandem mass spectrometry
}

\author{
Josep Sanchís • Lina Kantiani • Marta Llorca • \\ Fernando Rubio • Antoni Ginebreda • Josep Fraile • \\ Teresa Garrido • Marinella Farré
}

Received: 23 March 2012 / Accepted: 28 March 2012 / Published online: 18 April 2012

(C) Springer-Verlag 2012

Erratum to: Anal Bioanal Chem

DOI 10.1007/s00216-011-5541-y

Unfortunately, there is a typing error in the Applicability of the method section. The analysis was performed on 129 samples as is indicated in Table 6 . The percentage of positive samples should, therefore, always read $47 \%$ as it is indicated in the text.

In the last paragraph of the Results and discussion section "pictogram-per-litre" should correctly be "pictogram-permillilitre (ppt)".

\footnotetext{
The online version of the original article can be found at http://dx.doi.org/ 10.1007/s00216-011-5541-y.

J. Sanchís $\cdot$ L. Kantiani $\cdot$ M. Llorca $\cdot$ A. Ginebreda $\cdot$ M. Farré $(\triangle)$ Institute of Environmental Assessment and Water Research

(IDAEA-CSIC),

C/Jordi Girona, 18-26,

08034 Barcelona, Spain

e-mail: mfuqam@cid.csic.es

F. Rubio

Abraxis LLC,

54 Steam Whistle Drive,

Warminster, PA 18974, USA

J. Fraile $\cdot$ T. Garrido

Catalan Water Agency,

Provença 204-208,

08036 Barcelona, Spain
} 